\title{
A METODOLOGIA DE PESQUISA EM SALA DE AULA NA FORMAÇÃO E NA ATUAÇAOO DOCENTE
}

\author{
CLASSROOM METHODOLOGY RESEARCH IN RELATION TO THE TEACHERS' \\ FORMATION AND PRAXIS
}

\section{LA METODOLOGÍA DE INVESTIGACIÓN EN CLASE EN LA FORMACIÓN Y EN LA ACTUACIÓN DOCENTE}

Nilda Stecanela*

nildastecanela@gmail.com

\begin{abstract}
REVISTA PEDAGÓGICA
Revista do Programa de Pós-graduação em Educação da Unochapecó | ISSN 1984-1566

Universidade Comunitária da Região de Chapecó | Chapecó-SC, Brasil

Como referenciar este artigo: STECANELA, N. A metodologia de pesquisa em sala de aula na formação e na atuação docente. Revista Pedagógica, Chapecó, v. 17, n. 35, p. 163-178, maio/ago. 2015.
\end{abstract}

\begin{abstract}
RESUMO: O texto tem como ponto de partida a reflexão sobre os desafios da educação contemporânea, cujos enfrentamentos requerem intervenções pedagógicas qualificadas e inovadoras. No seu desenvolvimento, descreve-se uma prática vivida no contexto da formação docente com vistas à construção de respostas para a recorrente indagação: como fazer?". Define como pontos "de chegada o debate sobre a prática docente na Educação Básica relacionando o uso da pesquisa em sala de aula como uma metodologia de ensino possível. Na tessitura da argumentação, defende o protagonismo do professor, em permanente processo de formação, no sentido de desenvolver a competência reflexiva e a transposição didática na organização do seu ensino, de modo a conferir autoria ao seu fazer.
\end{abstract}

PALAVRAS-CHAVE: Educação contemporânea. Pesquisa em sala de aula. Formação Docente. Atuação Docente.

ABSTRACT: The text defines as its main objective the discussion about the teacher praxis in the Elementary school connecting the research in the classroom to a possible methodology of teaching. It is based on the contemporary education challenges, which questions demand new and qualified approaches. On the development of the text it is described a real praxis in the context of the teachers formation, aiming to find some answers to the repeated question: "How to implement the necessary change?" It defends the main role of the teacher, who is considered as a professional in constant formation, in order to develop a reflexive competence as well as transferring it to his/her pedagogical praxis.

KEYWORDS: Contemporary education. Classroom research. Praxis.

RESUMEN: El texto tiene como punto de partida la reflexión sobre los desafíos de la educación contemporánea, cuyos enfrentamientos requieren intervenciones pedagógicas cualificadas e innovadoras. En su desarrollo, describe una práctica vivida en el contexto de la formación docente con vistas a la construcción de respuestas para la recurrente indagación: Cómo hacer? Define como puntos de llegada el debate sobre la práctica docente en la Educación Básica relacionando el uso de la investigación en clase como una metodología de enseñanza posible. En la tesitura de la argumentación, defiende el protagonismo del profesor, en permanente proceso de formación, en el sentido de desarrollar la competencia reflexiva y la transposición didáctica en la organización de su enseñanza, de forma que confiera autoría a su acción.

PALABRAS CLAVE: Educación contemporánea. Investigación en clase. Formación Docente. Actuación Docente. 


\begin{abstract}
* Doutora e mestre em Educação pela Universidade Federal do Rio Grande do Sul (UFRGS). Foi bolsista CAPES em Estágio de Doutorado no Instituto de Ciências Sociais da Universidade de Lisboa em 2005 e 2006. Integra o corpo docente do Centro de Ciências Humanas e da Educação e do Programa de Pós-Graduação em Educação da Universidade de Caxias do Sul (UCS). Coordena o Observatório de Educação da UCS. É coeditora da Revista Conjectura: Filosofia e Educação. Atualmente é bolsista CAPES em Estágio Pós-Doutoral no Instituto de Educação da Universidade de Londres (IOE), onde possui vínculo como Honorary Research Associate.
\end{abstract}

\section{INTRODUÇÃO: OS DESAFIOS DA DOCÊNCIA NA EDUCAÇÃO BÁSICA}

A formação inicial de professores para atuação na Educação Básica tem exigido das instituições de Ensino Superior o enfrentamento de desafios, entre os quais a necessidade de preparação para atuação docente em contextos em que a diversidade sociocultural é o elemento transversalizador das práticas que perpassam o cotidiano dos processos educativos, escolares e não escolares, nos vários níveis e modalidades de ensino.

O cenário educativo brasileiro nos últimos 27 anos vem processando mudanças voltadas à concepção da educação como um direito humano, desencadeadas pela democratização do acesso à escola e à escolarização obrigatória.

Na história recente da educação brasileira, a Constituição da República de 1988, o Estatuto da Criança e do Adolescente de 1990 e a Lei de Diretrizes e Bases de 1996 podem ser considerados eventos de referência no desencadeamento de um processo que Canário (2006) denominou de mutação da escola. O esforço de universalização da Educação Básica, combinado com as políticas de proteção aos direitos da criança e do adolescente e com a revisão das concepções de educação, especialmente as relacionadas com os processos avaliativos, desafiam a escola a se reorganizar para receber aqueles que estavam fora dela e a tratá-los com dignidade. Desnaturalizam-se assim os processos de exclusão escolar, e a escola passa a acolher os filhos das classes trabalhadoras, as quais haviam interiorizado os baixos investimentos nos processos de escolarização das gerações em formação.

Narrativas de professores, tomadas em contextos de investigação e formação, indicam a associação do vivido em suas práticas muito mais como crise do que como processo de mutação da escola, visão antagônica à de Canário (2006). Os significados presentes em narrativas produzidas sobre o cotidiano da escola indicam que as práticas, efetivadas a partir do projeto moderno idealizado para ela, mostram-se impotentes ante os novos cenários e atores que transversalizam os processos educativos contemporâneos.

As justificativas para as dificuldades enfrentadas na ação cotidiana associam-se, de modo geral: à ausência da família na escolarização dos filhos; à falta de interesse dos jovens em aprender o que a escola quer ensinar; à indisciplina e falta de limites; à impotência dos professores frente aos direitos dos alunos; ao processo de vitimização do professor, sobrecarregado em suas tarefas, desvalorizado e desqualificado profissionalmente.

Sob outra ótica, um olhar distanciado sobre o vivido, para além das culturas da reclamação que emergem do percebido sobre o cotidiano escolar, pode levar a perceber a mutação pela qual a escola passa, estimulando não apenas a identificação dos problemas, mas mudanças nos modos de fazer. O devido distanciamento do cotidiano da prática 
docente pode possibilitar: a conversão dos problemas em necessidades, a definição de objetivos para superá-las e a escolha de alternativas de mediação para intervir na realidade e transformá-la. Dizendo de outra forma, a didática em suas dimensões técnica, política e humana é convocada a contribuir auxiliando a prática docente na organização do ensino diante dos novos cenários educativos, tendo o trabalho com a diversidade sociocultural como um dos maiores desafios.

Os modos de conceber e de perceber a ação docente perpassam aspectos inseparáveis do processo de formação e da competência reflexiva do professor (PERRENOUD, 2002), especialmente ao considerar as concepções de educação que mais promovem a cidadania sem, contudo, deixar de levar em conta outros elementos, como o método de ensino. Tal afirmação supõe que refletir sobre a prática incita uma análise da realidade e, consoante às concepções de educação que ancoram a atuação docente, requer escolha de caminhos de mediação para atender às demandas que o estudo da realidade indica. Em outras palavras, o método de ensino adotado, junto com os demais elementos constitutivos do planejamento da ação educativa - análise da realidade, objetivos, metodologia, conteúdos, referenciais teóricos, tempos e espaços, avaliação -, pode conferir um caráter inovador à prática e se aproximar do necessário enfrentamento dos desafios contemporâneos da Educação Básica que, conforme formula Canário (2006), são atravessados por fatores endógenos e exógenos e provocam o insucesso escolar.

Por meio do método de ensino que utiliza, o professor pode: promover a transposição didática, fundamentada por Chevallard (2005); contribuir com a transformação do conhecimento historicamente construído pela humanidade em conhecimento escolar, aproximando os interesses e as necessidades dos alunos; desafiar a superação da consciência ingênua em direção à consciência epistemológica das quais nos fala Freire (1997), garantindo, assim, o rigor científico necessário aos processos de construção do conhecimento.

Os preceitos até aqui apresentados reproduzem-se nos discursos dos professores que atuam na Educação Básica e dos alunos das licenciaturas. No entanto, em situações de prática de ensino, seja permeando os currículos dos cursos de formação, seja na atuação cotidiana das trajetórias profissionais, muitas perguntas são formuladas, dentre as quais a que ecoa com mais intensidade: "mas, como fazer?" Qual metodologia de ensino dá conta do anteriormente exposto?

Considerando as afirmativas de Becker (2007) sobre as potencialidades que têm a constituição de um professor reflexivo e pesquisador de sua prática, de modo a agregar elementos para intervir na realidade, transformá-la e promover aprendizagens significativas, coadunamos com os ensinamentos de Moraes e Lima (2004), ao defenderem o 
${ }^{1}$ Privilegio as expressões no feminino, pois na edição da disciplina cuja experiência é narrada no texto havia apenas alunas na turma. Usarei professor/es ou alunos apenas para referências generalizantes. uso da pesquisa em sala de aula como método de trabalho. Mais do que os procedimentos envolvidos nessa metodologia de ensino está o trabalho pedagógico com os saberes prévios dos alunos como ponto de partida. Na sequência, ampliam-se as possibilidades de construção do significado da experiência escolar, associando os saberes da escola com os saberes da vida. É, também, uma alternativa para a efetivação do direito à educação, ultrapassando a garantia do acesso em direção à permanência e ao sucesso de crianças, jovens e adultos que procuram a Educação Básica. Dizendo de outro modo, assegurando o direito à aprendizagem.

Com base no exposto, o texto relata uma experiência que focaliza o uso da pesquisa como ferramenta pedagógica, tanto na formação como na atuação docente, vivenciado numa disciplina que integra a organização curricular de um curso de Licenciatura. Procura, além disso, estabelecer conexões entre o momento da formação e o da atuação docente, construindo argumentos sobre a importância que tem o planejamento na sinalização de caminhos, no zelo pela trilha e na aposta pela chegada, desafiando a assunção da autoria do fazer pedagógico.

A partir da exploração das dimensões conceituais, procedimentais e atitudinais dos conteúdos acadêmicos atinentes à referida disciplina e recorrendo à pesquisa em sala de aula como ação mediadora, professora e alunas ${ }^{1}$ tiveram a oportunidade de transitar por tema até então pouco explorado na trajetória de formação acadêmica, mas que emergiu das discussões desencadeadas durante as aulas. Assim, a reflexão sobre a constituição da docência no contexto dos direitos humanos e do direito à educação, foi o tema escolhido pela turma para desenvolver as competências para o processamento da análise crítica da prática docente, objeto central da disciplina.

\section{O CENÁRIO DE UMA PRÁTICA}

A inclusão da análise crítica da prática docente no currículo de um curso de formação de professores justifica-se pela intenção de provocar a elaboração e a expressão das sínteses do conhecimento, em diálogo com a realidade educacional na qual a maior parte dos egressos atuará: as redes de ensino pública e privada da região onde a instituição que acolhe o curso se insere. O desafio da disciplina envolve a revisitação do caminho feito através de múltiplos princípios, conceitos e procedimentos, conhecidos e apropriados, colocados em movimento nas práticas pedagógicas experimentadas, de modo longitudinal, na programação de cada disciplina e, de modo específico, nos estágios curriculares que integram o curso.

Desafiar a tessitura da crítica à prática docente implica conceber a relação teoria-prática de forma indissociada e intimamente articulada, por compreender que o objeto de análise - a atuação docente - é também objeto de investigação. Esse processo é exigente, pois provoca a evocação 
de competências desenvolvidas, nem sempre identificadas, no sentido de formular uma apreciação de cunho epistemológico e envolto em consciência ética e estética, atinentes à natureza da crítica, como modo de expressão do exame da prática docente.

Os desafios se ampliam, pois múltiplas são as interfaces da atuação docente, nos múltiplos contextos em que a docência é constituída e exercida. Neste ponto entra a dimensão da pesquisa como princípio educativo (DEMO, 2007) de modo a promover a formulação da crítica, a partir dos saberes prévios dos sujeitos envolvidos - as alunas do curso - e dos seus focos de interesse sobre os cenários da atuação docente.

Assim, a proposta de trabalho da disciplina procura discutir aspectos relacionados aos cenários da formação e da atuação docente, retomando conceitos transversais mutação da escola; fatores endógenos e exógenos do insucesso escolar; professor reflexivo; professor pesquisador; interdisciplinaridade; dimensões da didática, do conteúdo e do planejamento; concepções de avaliação; pilares da educação; ética e política na educação; entre outros -, a fim de desencadear a explicitação de inquietações sobre a prática docente, explorar suas interfaces, promover a escolha de focos específicos de análise, converter curiosidades em projeto de pesquisa a ser elaborado e desenvolvido. Entre as habilidades desencadeadas, envolve também o tratamento da informação, através da organização e da interpretação de dados, a sistematização dos resultados, e a apresentação do processo e das conclusões.

A disciplina é semipresencial, mediada pelas ferramentas do Ambiente Virtual de Aprendizagem (AVA) disponibilizado no portal da universidade que ancora o curso, com a realização de aproximadamente $20 \%$ das aulas na modalidade a distância (EaD). A oferta é semestral e acontece em turma única a cada semestre.

A cada semestre, diferentes recortes da atuação docente emergem como focos de interesse das turmas para a investigação e tessitura da crítica. Entre os mais recorrentes estão: os desafios de ser professor; o planejamento da prática pedagógica e os modos de ensinar; a atuação docente em diferentes modalidades e na educação inclusiva. Raros foram os interesses sobre educação rural, educação em prisões ou gestão escolar. Em seis edições da disciplina, as questões de gênero e a Educação indígena não atraíram o interesse investigativo, indicando a necessidade de sensibilização do olhar das estudantes para esses cenários da atuação.

Na versão da disciplina que este texto se refere, ocorrida no primeiro semestre de 2013, a escolha recaiu sobre a constituição da docência na era dos direitos humanos, agregando discussão sobre as percepções dos professores em exercício da docência em relação às suas práticas e as associações que costumam fazer, direta ou indiretamente, com os efeitos do direito à educação em suas trajetórias. 


\section{DOS OBJETIVOS ÀS FORMAS DE TRATAMENTO DIDÁTICO}

O programa da disciplina tem como objetivos: oportunizar o desenvolvimento de argumentos crítico-reflexivos a partir da observação da sala de aula e da realidade escolar; promover a construção de princípios que orientem a crítica da prática pedagógica; compreender a pesquisa como princípio educativo; fundamentar a crítica a partir de conceitos ético-pedagógicos.

Entre os conteúdos curriculares, na dimensão conceitual, a disciplina prevê a abordagem dos tópicos: Princípios da prática pedagógica; Saberes da formação docente; Ética e política na educação; Prática reflexiva do professor; Pesquisa como princípio educativo; Formação continuada do professor; Postura interdisciplinar; Perfil do egresso.

Os conteúdos conceituais são abordados de modo relacional com os conteúdos atitudinais e procedimentais e contemplam os dizeres de Marques (2001) ao tomar a pesquisa como princípio da aprendizagem e a escrita como princípio da pesquisa. Deste modo, todas as atividades propostas na disciplina apresentam momentos de: educação do olhar da observação (FREIRE, 1996); reflexão sobre a prática docente; e registros do processo.

A educação do olhar da observação é oportunizada através do direcionamento para os cenários educativos contemporâneos, instigando a adoção de uma postura investigativa: mais do que procurar respostas, esse olhar formula perguntas que orientem uma análise distanciada do imediatismo que acomete o cotidiano das instituições de ensino na atualidade.

A reflexão sobre o vivido presta especial atenção para as narrativas produzidas sobre o cotidiano educativo e que são naturalizadas na voz de alguns atores, procurando alcançar as frequências dos ecos que as culturas escolares e institucionais produzem nas práticas e na relação pedagógica.

Os registros do processo acontecem em vários momentos, em diferentes suportes e através de diferentes gêneros textuais: relatos de aula; fichas de leitura; seminários de estudos; fóruns de discussão, narrativas orais, leituras comentadas, construção e desenvolvimento de projeto de pesquisa com sistematização e apresentação dos resultados. As produções são acompanhadas por um processo de interação/devolução, comentados pela professora no corpo dos textos, de modo a estimular a metacognição e facilitar a compreensão do processo, em aproximações sucessivas aos pontos de chegada estimados para cada atividade.

A intenção é abordar as três dimensões do conteúdo - conceitual, procedimental e atitudinal - de modo equitativo, deslocando a tradicional supremacia conceitual em direção ao estabelecimento de equilíbrio entre os conceitos, os procedimentos e as atitudes. 
${ }^{2}$ A disciplina contou com a presença de uma monitora advinda da graduação e de um estagiário oriundo do mestrado em educação.
O suporte que acolhe os produtos que a mediação didática desafia à construção é o AVA. Nas ferramentas do AVA, todos os roteiros de aula, construídos no formato de cartas direcionadas aos participantes da turma, são disponibilizados previamente. O conteúdo das cartas procura situar: uma breve retomada da aula anterior, os objetivos da aula do dia, a descrição dos procedimentos, a indicação dos suportes teóricos e, ao final, alguns indicadores de aprendizagem, de modo a orientar a reflexão que cada aluna é desafiada a fazer sobre a aula, postando o resultado no webfólio do AVA, na pasta Relatos de aula.

Um mural de recados é utilizado para comunicar as modificações/inserções realizadas no espaço virtual da disciplina. O cronograma com a sinopse e o detalhamento de cada aula é atualizado semanalmente. Na pasta Acervo da Turma são publicados textos de apoio ou indicativos de links para acesso, além de produções coletivas da turma, parciais e finais. Cada aluna tem uma pasta em seu nome para postagem das atividades individuais, e cada grupo de pesquisa tem outra para postagem das atividades coletivas.

Assim, todo o desenvolvimento da disciplina é registrado e arquivado no suporte virtual, ficando à disposição para consultas futuras, tanto da professora como das alunas. O AVA configura-se em potente recurso de mediação pedagógica e contribui para a conquista dos princípios da interatividade, da dialogicidade e da afetividade.

A linguagem dos materiais didáticos postados no AVA tem o cuidado de manter a proximidade entre professora e alunas de modo que leitura e escrita se façam presentes, a todo o momento, combinadas com a construção de argumentos em linguagem oral, individualmente, no grupo e na turma. Essa postura associa-se à concepção da pesquisa na sala de aula como um jogo de linguagens, mediado pela fala, pela leitura e pela escrita. A esse respeito, os ensinamentos de Moraes (2007, p. 6) indicam que "Aprende-se falando, lendo e escrevendo, sempre tendo como foco problemas pertinentes e com significado para os participantes", e acrescenta: "Transformar a sala de aula em espaço de pesquisa é assumir que o conhecimento e a verdade estão em constante movimento de reconstrução".

Além das comunicações no mural e demais pastas do AVA, o diálogo pedagógico pode ser potencializado pelo recurso de mensagens instantâneas disponíveis, favorecendo conversas entre os participantes da turma: professora, estagiário, monitora e alunas ${ }^{2}$.

\section{O PROJETO DE PESQUISA COMO MEDIAÇÃO NA ANÁLISE CRÍTICA DA ATUAÇÃO DOCENTE}

O principal recurso para a construção das aprendizagens na experiência narrada é o projeto de pesquisa, o qual começa a ser gestado desde a primeira aula, com avanços gradativos nas etapas de planejamento e execução 
${ }^{3} \mathrm{O}$ que queremos saber sobre o tema de nossa pesquisa? O que você já sabe sobre o assunto que queremos pesquisar? O que você pretende esclarecer com a pesquisa sobre este tema? Que hipóteses você tem sobre o assunto? Em sua opinião, diferentes grupos de pessoas têm diferentes opiniões? Quais são os diferentes aspectos implicados no problema? O que você pretende fazer com os resultados da pesquisa? Para quem os dados deveriam ser divulgados? dos itinerários investigativos, tomando por objeto as temáticas que emergem nas discussões e reflexões realizadas, de modo a possibilitar a análise crítica da prática docente, considerando os recortes definidos pela turma.

Mais do que os resultados da pesquisa, merece destaque a experiência vivida através de uma metodologia de ensino ativa, desde o lugar de alunas do ensino superior. Esta, por simetria invertida, poderá inspirar a organização do ensino na Educação Básica, quando forem professoras.

Os referenciais teóricos da disciplina procuram desafiar o olhar para os processos educativos, relacionando-os às vivências das alunas da turma como ex-alunas ou como professoras em exercício da docência. A leitura dos autores indicados como referência teórica da disciplina - Canário (2006), Rios (2003), Cunha (2001), Perrenoud (2002), Freire (1997), entre outros - remete à análise da gênese da crise da escola e aos desafios da constituição da docência na contemporaneidade.

A relação entre direitos humanos e educação, como chamada geral para o projeto de pesquisa desenvolvido, decorreu das discussões provocadas pelas palavras dos autores trazidos para a sala de aula. O segundo momento envolveu a compreensão da proposta da disciplina em recorrer à pesquisa como princípio educativo para o desenvolvimento da crítica à prática docente pelo viés dos direitos humanos. A pesquisa em aula constituiu-se em recurso para a exploração dos conteúdos da disciplina, transversalizados pela temática definida a partir das discussões feitas: a constituição da docência na era do direito à educação.

Leituras de autores que tratam da pesquisa em sala de aula foram disponibilizadas para discussão - Demo (2007); Moraes (2007) -, mostrando, em partes, o caminho a ser percorrido, pelo planejamento das etapas de um projeto de pesquisa. Além disso, foi projetado um vídeo documentário que ilustra uma experiência de pesquisa em sala de aula, realizada na Educação Básica, com o intuito de testemunhar possibilidades de construção de conhecimentos significativos.

Iniciou-se pelo levantamento dos saberes prévios da turma sobre o tema da pesquisa, através de respostas a oito perguntas orientadoras ${ }^{3}$, com o foco nos direitos humanos, respondidas individualmente e, depois, reunidas sob orientação das formulações de Gandin (1994) a respeito da importante tarefa de reunir ideias. Nessa etapa, quatro grupos de pesquisa já estavam formados. A cada grupo, foi destinado um conjunto das respostas da turma a determinadas perguntas com a tarefa de reunir as ideias em um texto coeso, preservando a originalidade das narrativas. Os textos compostos pelos grupos foram reunidos num único texto e, na aula seguinte, foi submetido à leitura da turma, para apreciação e inserção dos referenciais teóricos que fundamentaram os conceitos explicitados direta ou indiretamente. Neste momento, um conjunto de textos sobre direitos humanos, formação de professores em direitos 
humanos, direito à educação, carta universal dos direitos humanos, entre outros, foi disponibilizado para consulta, ampliando o recorte do conhecimento inicialmente definido para o semestre. Cada grupo escolheu uma cor de fonte e inseriu suas contribuições no corpo da primeira versão compactada do texto. Novamente as contribuições dos grupos foram materializadas em um único texto que já apresentava características de uma justificativa para constar do projeto de pesquisa.

Numa terceira versão, o texto foi novamente submetido à apreciação dos grupos de modo a identificarem indícios: da justificativa, do tema, do subtema, do problema, dos objetivos, da metodologia e dos referenciais teóricos que sustentavam as relações estabelecidas. Essa etapa foi acompanhada de um roteiro didatizado para a construção de projeto de pesquisa, com notas de rodapé explicativas para cada fase.

As versões preliminares de cada projeto organizado pelos grupos foram reunidas em um único texto que, após nova apreciação da turma, a inserção de cronograma, a definição de população e da amostra da pesquisa, deu origem a um projeto coletivo intitulado "Educação e direitos humanos: a constituição da docência na era dos direitos". Os interlocutores empíricos da turma foram professores dos anos iniciais do Ensino Fundamental atuantes em escolas públicas, numa amostra aleatória que contemplou 21 entrevistados. Com base nas interações estabelecidas, a pesquisa foi sendo gestada, tendo a professora como guardiã do processo e dos pontos de chegada, e as alunas como parceiras e autoras de ambos.

Para a realização do trabalho de campo, foi disponibilizado um material teórico sobre a construção dos instrumentos de pesquisa, aliado às orientações sobre o desenvolvimento do trabalho de campo. Cada grupo teve a incumbência de elaborar pelo menos uma pergunta para cada uma das modalidades referidas no texto indicado. As questões sugeridas foram postadas no AVA, reunidas em um único instrumento, dividido em quatro partes, aproximando as perguntas semelhantes: dados de identificação; desafios da educação no Século XXI; o direito à educação; Educação e Direitos Humanos.

Uma primeira versão do instrumento de pesquisa foi submetida à apreciação da turma e, em plenária, houve a decisão de quais perguntas permaneceriam, quais seriam reformuladas e quais seriam excluídas. Discussão, argumentação, escolhas e respeito à ideia do outro foram elementos presentes nessa fase. $\mathrm{O}$ instrumento em versão final, com 47 questões abertas e fechadas, foi anexado ao projeto de pesquisa e postado no AVA, disponibilizando um produto construído coletivamente.

As respostas das entrevistas foram digitadas e postadas numa pasta do AVA, com acesso aberto aos participantes da turma. Em sala de aula, após uma reflexão coletiva a respeito do trabalho de campo, com as primeiras 
impressões sobre os resultados, o conjunto de respostas foi distribuído entre os grupos para tabulação. Orientações referentes à tabulação e organização do banco de dados foram feitas em assessoria a cada grupo. As informações constantes nas tabelas organizadas em cada grupo foram reunidas e disponibilizadas em pasta específica do Acervo da Turma, a fim de que todas pudessem observar suas inferências nas respostas dos entrevistados.

Os contornos analíticos sobre a prática docente tomaram relevo pelas ênfases que cada grupo imprimiu ao que observou e extraiu do banco de dados. De posse do arquivo com a tabulação geral, cada grupo definiu uma interface relativa ao tema do projeto para descrever, analisar e interpretar.

O suporte para acolher as reflexões dos grupos privilegiou o gênero textual artigo. Para orientar a construção, foi disponibilizado um arquivo com orientações sobre aspectos estruturais de um artigo científico. A construção do texto com as análises dos grupos sobre o percurso da pesquisa, procurando dar voz aos números e interpretando as narrativas dos entrevistados, seguiu um processo de idas e vindas, com produção dos grupos e interação da professora através das ferramentas do Word - inserir comentários ou controlar alterações -, considerando a produção textual, reflexiva e analítica como um processo sempre passível de qualificação. A culminância foi quatro artigos, construídos de forma gradativa, em condições de serem socializados em espaços para além da sala de aula. Respectivamente, os grupos nomearam seus artigos com os seguintes títulos:

- Educação e direitos humanos: reflexos do direito à educação na atuação docente

- Direitos humanos no âmbito escolar: docência e discência

- A educação perpassada pelos direitos humanos: como lidar com essa realidade?

- Formação continuada e direitos humanos: uma reflexão necessária

Orientações para a apresentação dos resultados foram disponibilizadas e, através do gênero textual apresentação, os grupos organizaram slides contendo: objetivos de cada texto; percursos de sua construção; análises sobre a relação entre direitos humanos e educação e constituição da docência; problematização dos dados empíricos; e, por fim, a explicitação das aprendizagens construídas e as perspectivas do uso da pesquisa em aula nas práticas docentes.

A participação espontânea num evento científico sobre a especificidade do encontro possível entre a escola e a pesquisa, ampliou a abrangência do semestre letivo e oportunizou às alunas, além de apresentarem os resultados de suas pesquisas, observarem os resultados dos projetos desenvolvidos por professores e alunos da Educação Básica, envolvendo os anos iniciais e finais do Ensino Fundamental e também o Ensino Médio. Na ocasião, foi possível associar 
o movimento que a pesquisa, como princípio educativo, pode provocar nas aprendizagens de diferentes gerações e níveis de ensino. Alguns dos textos gestados na disciplina e apresentados no referido seminário foram publicados nos anais do evento.

\section{OLHANDO PARA O CAMINHO FEITO}

Relatar o caminho feito, observar o percurso e os pontos de chegada percorridos na trajetória da disciplina, cuja experiência este texto narra, desafia a identificar e a refletir sobre a inovação pedagógica implementada e a projetar a possibilidade de transposição do vivido no cotidiano do ensino superior para o da Educação Básica. Em que medida o vivido pode ser associado à inovação e quais as relações desta com os desafios da atuação docente na Educação Básica?

As formulações de Cunha (2008, p. 29), comunicam que "Compreender os impasses da prática pedagógica como uma possibilidade reflexiva e de problematização da ação docente já é, em si, uma inovação". Consoante às sínteses de Cunha, ousamos dizer que a prática relatada ultrapassou a mera inclusão de novidade ou de modismo e configurou-se, num tempo real e num espaço concreto, como produto da ação pedagógica colocada em movimento nos percursos da disciplina, além de potencializar princípios teórico-metodológicos disponíveis a todos. Neste caso específico, reconfigurou o conhecimento a respeito da prática docente e foi oportunidade de exercitar as competências de ler, escrever, falar e resolver problemas em equipe.

Sem a pretensão de superestimar a experiência desenvolvida, é possível observar sinais da presença de inovação pedagógica nos percursos da disciplina, à medida que: foi pautada por uma concepção não neutra de formação de modo a ultrapassar as fronteiras dos conteúdos conceituais listados, visando um equilíbrio entre os conteúdos procedimentais e atitudinais; procurou alimentar o diálogo numa perspectiva freireana, considerando que aquele que fala também escuta e quem escuta também tem o que dizer (FREIRE, 1987); a aparente dimensão abstrata dos conteúdos da disciplina ganhou outros contornos, agregou qualidade formal e política, conferiu autoria e autonomia nas produções das alunas, tanto na perspectiva oral, como na escrita; oportunizou a vivência de um caminho possível de inovar a prática docente, pelo uso pedagógico da pesquisa em sala de aula do Ensino Superior, o qual, por simetria invertida, também pode inspirar a prática docente na Educação Básica; considerou princípios epistemológicos e pedagógicos presentes nos referenciais orientadores da formação e da atuação docente e os transformou em conteúdos acadêmicos, desafiando a professora a construir materiais didáticos para efetivar as finalidades da disciplina; o tratamento metodológico escolhido para o desenvolvimento das aulas colocou professora e alunas frente ao desafio 
do novo, pois direitos humanos entraram na disciplina de modo transversal, conferindo significado ao apreendido, ampliando o horizonte de alcance inicialmente pretendido; além disso, estimulou a explicitação das relações estabelecidas nas inúmeras produções escritas partilhadas no AVA, culminando com uma sistematização tornada pública através do artigo, acolhendo as incompletudes e reforçando a dimensão processual da escrita e do pensamento humano.

A reflexão sobre a prática aqui apresentada também se aproxima dos dizeres de Cunha (2008, p. 20), uma vez que o professor "[...] ao ser instigado a falar sobre suas concepções e experiências, organiza seu pensamento e utiliza a narrativa como processo reflexivo". Consoante às afirmações da autora (2008, p. 34), os percursos vividos na disciplina conferiram à professora e às alunas uma possibilidade de "[...] dar sentido às suas práticas, para além da perspectiva pragmática da carreira e da formação instrumental [...]", considerando que o caminho, muito mais do que os pontos de chegada, ganha força, toma forma e mobiliza energias.

Outro momento importante do vivido é representado pela avaliação. O acompanhamento das aprendizagens aconteceu de forma processual e contínua, ancorado na concepção emancipatória de avaliação preconizada por Saul (1995), pois o interesse não estava em medir o conhecimento construído, mas em fazer vigília por ele, zelando para que aproximações sucessivas em direção ao inicialmente estabelecido fossem acontecendo.

Não se recorreu às tradicionais provas. A elaboração e expressão da síntese do conhecimento aconteceu por meio de outros instrumentos e no estabelecimento do diálogo entre os conhecimentos prévios, os interlocutores empíricos e os interlocutores teóricos. As alunas aprenderam a explicitar e organizar ideias, a argumentar, a olhar de outro modo, a colocar em causa o senso comum, a não se conformar com as primeiras impressões, elementos que fazem parte das finalidades da disciplina e envolvem a tessitura da crítica à prática docente, potencializadas pelo recurso feito ao projeto de pesquisa.

Um processo de desconstrução do olhar para as dicotomias do certo e do errado precisou ser empreendido, à medida que as produções disponibilizadas acolhiam interações para desestabilizar certezas e estimular uma argumentação qualificada.

Um conjunto de atividades contribuiu para a composição do conceito final de cada aluna para atender à dimensão formal da avaliação acadêmica: o fichamento de um dos livros indicados para leitura integral (CUNHA, 2001; RIOS, 2003), para alimentar o diálogo num dos seminários de estudos para discutir as interfaces da docência; uma metarreflexão sobre os relatos realizados a cada aula, indicando as aprendizagens significativas e aquelas por construir; a produção em equipe do artigo científico, contendo a sistematização das reflexões e das argumentações do grupo 
sobre uma das interfaces da docência, extraída do projeto de pesquisa; a apresentação oral dos resultados da pesquisa e das análises decorrentes.

Outros elementos foram coadjuvantes no processo avaliativo e na elaboração da síntese dos conhecimentos: as leituras comentadas de textos; os fóruns de discussão para estimular o diálogo e a produção argumentativa.

Houve também incentivo à evocação das produções parciais realizadas no semestre, para valorizar as partes na relação com o todo e compreender, a partir do vivido, como o diálogo pode ser alimentado no processo.

Destacam-se também os indicadores de avaliação, explicitados no plano de cada aula, pois configuraram a pauta de observação que orientou o olhar da professora para o desempenho da turma e de cada aluna para o registro dos seus próprios percursos.

\section{CONSIDERAÇÕES FINAIS: APONTANDO PARA OUTROS CAMINHOS}

A responsabilidade em efetivar o programa da disciplina e a necessidade de articular os conhecimentos acadêmicos com os saberes docentes, e destes com o cotidiano da Educação Básica, constituem-se elementos orientadores dos meus modos de fazer. Embora as intenções sejam desenhadas a priori, o caminho é sempre relativo, consoante à composição das turmas e às experiências dos que dela fazem parte, envolvendo também suas concepções de educação e visão de mundo. Por isto, os percursos acolhem atalhos, pontos de recuo, paradas obrigatórias, avanços, itens de contemplação do que está por vir e do caminho feito, além da negociação sobre mudanças de roteiro não previstas.

Os planos das aulas, organizados em cartas, foram cuidadosamente pensados para conferir a dialogicidade necessária à compreensão e à interpretação do que estava sendo proposto, diluindo no corpo do texto os elementos constitutivos do planejamento. Em igual medida, a arquitetura do AVA requisitava a articulação com o proposto nas cartas, de modo a ter as pastas abertas e organizadas para acolher as atividades desencadeadas e os referenciais indicados.

A disponibilização prévia dos planos de aula, assim como de textos produzidos pela professora, teve a intenção de testemunhar o possível, aproximando modos de dizer com modos de fazer. Antes mesmo de seduzir as alunas para o conteúdo e formato da aula, eu experimentava a entrega e a inteireza dos objetivos e caminhos de cada encontro.

Como exigir que nossas/os alunas/os das licenciaturas façam planejamentos qualificados e os desenvolvam em parceria com os seus alunos se, como formadores de professores, não partilhamos os caminhos que nós próprios construímos para o desenvolvimento de nossas aulas, no exercício de nossa docência no Ensino Superior? 
Não por acaso a constituição da docência acompanhou as elaborações do semestre, orientadas pelos sentidos atinentes ao verbo transitivo constituir, do qual se origina o substantivo constituição, conferindo-lhe a ideia de processo: ser, formar(-se), compor(-se). Desta forma, ser professor implica em constituir-se professor em permanente processo de formação.

Alguns impasses também se fizeram presentes, entre os quais as culturas de reprodução e/ou de leituras aligeiradas, que acabam atravessando a interpretação e compreensão das orientações. Toda disciplina passou pelo registro escrito, mas nem sempre as orientações eram lidas na íntegra. Nesses casos, certa passividade indicava a reprodução da cultura da espera e da necessidade em ter os registros traduzidos em pormenores pela professora, retardando a constituição da autonomia.

Em contrapartida, tive a alegria de acompanhar a trajetória de ex-alunas tornando-se professoras da Educação Básica, vindo a organizar suas práticas docentes com base na pesquisa como princípio educativo, desafiando seus alunos, e elas próprias, à aprendizagem do olhar. Inquietações do cotidiano puderam ser problematizadas a partir de diferentes ângulos com a construção de respostas possíveis consoante às condições de entrega ao proposto. No caminho e nos pontos de chegada, a construção gradativa da experiência, no professor e no aluno, pelo viés da pesquisa em sala de aula.

A vigilância em manter interligados o método escolhido para desenvolver a disciplina e o seu objeto de estudo foi exigida permanentemente, pois uma tendência para desviar o foco era ameaça constante, dando centralidade à pesquisa por ela mesma. Evidenciada também ficou a necessidade de explorar em maior profundidade os dados empíricos, de modo a descrevê-los, interpretá-los e colocá-los em causa, inserindo-os de forma mais efetiva no artigo produzido.

A pesquisa em sala de aula é um método de ensino e uma resposta possível à indagação “como fazer?”, mas não prescinde da reflexão sobre os meios para assegurar que o professor possa utilizá-la, conhecendo e experienciando o processo. Efetivá-lo como princípio educativo e potente ferramenta para a construção do conhecimento na Educação Básica requer a pesquisa no professor (DEMO, 2007) e o redesenho dos processos de formação de professores, em nível inicial e continuado. O objetivo é chegar à pesquisa no aluno pela mediação do professor da Educação Básica.

O texto sublinhou a intenção explícita de testemunhar que as vivências protagonizadas e narradas possam desencadear a construção de novas práticas, não como receita, mas como inspiração para observar e estabelecer a relação pedagógica, acolhendo e respeitando a dinamicidade que lhe é própria.

Explorar um objeto de estudo - a análise crítica da prática docente - por meio da pesquisa em sala de aula 
possibilita transitar pelo inusitado presente nos temas que emergem das inquietações dos participantes, a exemplo da relação dos direitos humanos e à educação com os desafios da constituição da docência na atualidade. As potências da pesquisa como princípio educativo ultrapassam a qualidade formal e política que acompanham o processo e ganham sentidos polifônicos nos percursos individuais e coletivos do grupo, sublinhando as potências dos modos de fazer testemunhados.

As respostas ao como fazer agregam saber e sabor à prática docente e à constituição da docência em cada aula, com cada grupo. O auditório do texto, constituído pelos leitores interessados na experiência narrada, juntamente com o imaginário que possivelmente as palavras desse texto venham a desencadear, poderão cumprir a tarefa de ampliar, criticar, mobilizar, esclarecer as incompletudes e as potências do exposto.

\section{REFERÊNCIAS}

BECKER, Fernando: MARQUES, Tânia Beatriz Iwasko (Orgs.). Ser professor é ser pesquisador. Porto Alegre: Mediação, 2007.

CANÁRIO, Rui. A escola tem futuro? Das promessas às incertezas. Porto Alegre: Artmed, 2006.

CHEVALLARD, Yves. La transposición didática: del saber sábio al saber enseñado. Tradução de Claudia Gilman, 3. ed. Buenos Aires: Aique Grupo Editor, 2005.

CUNHA, Maria Isabel da. O bom professor e sua prática. 13. ed. Campinas, SP: Papirus, 2001.

Inovações pedagógicas: o desafio da reconfiguração de saberes na docência universitária. Cadernos de Pedagogia Universitária. São Paulo, Universidade de São Paulo, p. 1-38, 2008.

DEMO, Pedro. Educar pela pesquisa. Campinas: Autores Associados, 2007.

FREIRE, Madalena. Observação, registro e reflexão. Instrumentos Metodológicos I. 2. ed. São Paulo: Espaço Pedagógico, 1996.

FREIRE, Paulo. Pedagogia da autonomia. Rio de Janeiro: Paz e Terra, 1997.

e Terra, 1987.

Pedagogia do oprimido. Rio de Janeiro : Paz

GANDIN, Danilo. A prática do planejamento participativo. Petrópolis, RJ : Vozes, 1994. 
MARQUES, Mario Osório. Escrever é preciso: o princípio da pesquisa. Ijuí: EdUnijuí, 2001.

MORAES, Roque. Participando de jogos de aprendizagem: a sala de aula com pesquisa. Seminário Escola e Pesquisa: um Encontro Possível, 7. Anais... Caxias do Sul, UCS, 2007.

; LIMA, Valderez Marina do Rosário (Orgs.). Pesquisa em sala de aula: tendências para a educação em novos tempos. Porto Alegre: EdiPUCRS, 2004.

PERRENOUD, Philippe. A prática reflexiva do ofício de professor: profissionalização e razão pedagógica. Porto Alegre: Artmed, 2002.

RIOS, Terezinha A. Compreender e ensinar: por uma docência da melhor qualidade. 4. ed. São Paulo: Cortez, 2003.

SAUL, Ana Maria. Avaliação emancipatória. Campinas: Cortez, 1995. 